\title{
Association of Kidney Biopsy Findings With Short- and Medium-Term Outcomes in Children With Moderate-to-Severe Iga Vasculitis Nephritis
}

\section{Stéphanie Clavé ( $\square$ stephanie.clave@ap-hm.fr)}

Assistance Publique Hopitaux de Marseille

\section{Maud Sordet}

CHU Bordeaux GH Pellegrin: Centre Hospitalier Universitaire de Bordeaux Groupe hospitalier Pellegrin

\section{Michel Tsimaratos}

Assistance Publique - Hôpitaux de Marseille: Assistance Publique Hopitaux de Marseille

\section{Stéphane Decramer}

Hôpital Purpan: Hopital Purpan

\section{Marc Fila}

Hospital Arnaud de Villeneuve: Hopital Arnaud de Villeneuve

\section{Vincent Guigonis}

Hospital Limoges

\section{Camille Faudeux}

University Hospital Centre Nice: Centre Hospitalier Universitaire de Nice

\section{Laurent Daniel}

Assistance Publique - Hôpitaux de Marseille: Assistance Publique Hopitaux de Marseille Julia Torrents

Assistance Publique - Hôpitaux de Marseille: Assistance Publique Hopitaux de Marseille Mohamed Boucekine

Aix-Marseille Universite de Provence: Aix-Marseille Universite

\section{Jérôme Harambat}

CHU Bordeaux GH Pellegrin: Centre Hospitalier Universitaire de Bordeaux Groupe hospitalier Pellegrin

\section{Caroline Rousset-Rouvière}

Assistance Publique - Hôpitaux de Marseille: Assistance Publique Hopitaux de Marseille

\section{Research Article}

Keywords: Immunoglobulin A vasculitis nephritis, pediatricpaediatric, Henoch Schönlein purpura, nephrotic syndrome, kidney biopsy, International Study of Kidney Disease in Children classification

Posted Date: March 15th, 2021 
DOl: https://doi.org/10.21203/rs.3.rs-293781/v1

License: (c) (1) This work is licensed under a Creative Commons Attribution 4.0 International License. Read Full License 


\section{Abstract}

Assessing the initial severity of immunoglobulin A vasculitis nephritis (IgAV-N) is challenging important due to its determining effect on kidney management and outcomes. This study paper aims to describe describes a multicentre paediatric multicenter pediatric cohort of IgAV-N patients and discusses whilst investigating the relationships among between clinical presentation, histological features, and kidney outcome. A cohort consisting of 170 children requiring early kidney with biopsy because of IgAV-N, which was diagnosed between 2007 and 2017, was assessed including 27\% of children with nephrotic syndrome (NS). One-quarter of the cohort (27\%) presented with initial nephrotic syndrome (NS). Kidney biopsy revealed International Study of Kidney Disease (ISKDC) grade II or grade III in $83 \%$ of cases. An International Study of Kidney Disease (ISKDC) grade II or grade III was revealed through kidney biopsy in $83 \%$ of cases. Endocapillary proliferation was were observed in $73 \%$ of patients, and chronic lesions were observed in $25 \%$ of patients. Data analysis demonstrated showed a significant association between clinical severity (NS at onset and histological findings such asendocapillary proliferation and cellular crescents. After a median follow-up of 21 months (IQR 12-39), 30\% of patients had persistent kidney impairment (proteinuria or decreased eGFR. WorseAt the end of follow-up, kidney outcome impairment was significantly associated more often observed in patients with NS at onset and those with cellular crescents and chronic lesions on initial kidney biopsy.

Conclusions: This study highlights the relationship between the clinical and histological presentation of IgAV-N and the factors that affect kidney outcome. The ISKDC classification may be improved by including lesions that are more discriminating for disease severity and prognosis.

\section{What Is Known}

- Nephrotic syndrome or kidney failure at diagnosis and cellular crescents in more than $50 \%$ of the glomeruli are recognized as risk factors for poor kidney outcome in immunoglobulin A vasculitis nephritis (IgAV-N).

- The reference histological classification of IgAV-N comes from the International Study of Kidney Disease in Children (ISKDC) primarily based on the presence and number of affected glomeruli (mesangial proliferation, cellular crescents). The updated Oxford classification, which emphasizes tubular atrophy and interstitial fibrosis, was also used to group pathologic features of IgAV-N. Both classifications have limitations.

\section{What Is New}

- Since NS at diagnosis is associated with initial histological severity and poorer kidney outcome, in patients with IgAV-N and NS, kidney biopsy should not postpone medical treatment. This proposal needs to be verified in further studies.

- Endocapillary proliferation is associated with the initial severity of IgAV-N at diagnosis. 
- Chronic glomerular changes and interstitial fibrosis are associated with poorer short- and mediumterm kidney

\section{Introduction}

Immunoglobulin A vasculitis (IgAV), known as Henoch-Schönlein purpura, is the most common vasculitis in childhood, with a reported yearly incidence of 6 to 20 per 100000 children (1). The prognosis of IgAV is usually good, but kidney impairment is the main cause of morbidity and mortality and the main determinant of long-term outcome (2). IgAV nephritis (IgAV-N) occurs in approximately one-third of cases. In the literature, about $20 \%$ of IgAV-N patients develop nephrotic syndrome (NS) at diagnosis, occasionally associated with acute kidney injury (3-5). The risk of progression to chronic kidney disease (CKD) has been reported to range from 1 to $36 \%(6-10)$. This wide variability can be explained by selection bias (such as the inclusion of patients with more-or-less severe IgAV-N depending on the type of treatment centre, secondary paediatric care or tertiary referral centre), differences in the definition of CKD, or the follow-up duration.

The clinical severity (NS, acute kidney injury) or histological features (cellular crescents in more than $50 \%$ of the glomeruli) of IgAV-N at disease onset have been considered to be predictive of poor kidney outcome in children $(7,8,11,12)$. However, in many other studies, these histological features are not associated with IgAV-N prognosis $(8,10,11,13,14)$. To date, the literature findings on the association between a specific histological lesion and the IgAV-N prognosis are conflicting.

Kidney biopsy remains the gold standard in assessing the severity of IgAV-N with the reference histological classification of IgAV-N by the International Study of Kidney Disease in Children (ISKDC), dating back to 1977 (15). The ISKDC classification is based mainly on the presence and number of affected glomeruli (mesangial proliferation, cellular crescents). In addition, the Oxford classification of $\lg$ A nephropathy was developed as a classification of biopsy findings in adults with IgA-N. This is a more extensive classification than the ISKDC classification, which describes not only mesangial hypercellularity but also endocapillary proliferation, glomerulosclerosis, and interstitial fibrosis/tubular atrophy (16). IgAV-N and IgA nephropathy have previously been considered the two different manifestations of a single disease, with many similarities. The Oxford classification has therefore been applied for reviewing biopsies of adults and children with IgAV-N (17).

In 6 paediatric nephrology units in southern France, we have shared the same diagnostic algorithm and treatment protocol for IgAV-N for the past 10 years. In evaluating our kidney biopsy practices, this retrospective analysis aims to describe the presentation of biopsy-proven IgAV-N in a paediatric cohort and the relationship between clinical and histological features at diagnosis and during short- and medium-term follow-ups of kidney disease.

\section{Method}




\section{Study design}

We performed a retrospective multicentre analysis of a historic cohort of children with IgAV-N in paediatric nephrology units of Bordeaux, Limoges, Marseille, Montpellier, Nice, and Toulouse from 2007 to 2017. All patients who were 1 to 18 years of age at the time of IgAV onset with a clinical diagnosis of IgAV according to the European League against Rheumatism (EULAR) classification (18) and biopsyproven IgAV-N were considered for inclusion. The patients were identified through pathology databases of the participating centres. The management of patients was based on a common protocol implemented in 2007 (supplementary data S1). The study was approved by the ethics committee of the French Society of Paediatrics (CER_SFP_2018_079-3).

\section{Data collection}

All children were examined by general practitioners or referred to local hospitals at the onset of purpura and extrarenal symptoms. The children were then systematically referred to paediatric nephrology units a few days later at the onset of IgAv-N. All kidney biopsies were performed in trained paediatric nephrology centres. Kidney biopsies were performed according to the same pre-established protocol (see Supplementary data S1). The indications for the first kidney biopsies included uncertainty about the aetiology of the nephritis, moderate IgAV-N of undetermined onset, severe IgAV-N, rapidly progressive glomerulonephritis and/or inefficacy of a well-conducted treatment after 1 month.

At the time of kidney biopsy (or in the previous week), the following clinical and biochemical data were collected from hospitalization files: extrarenal symptoms, blood pressure, kidney function, serum albumin and proteinuria. Hypertension was defined as a systolic or diastolic blood pressure $\geq$ the $95^{\text {th }}$ percentile for age, sex and height (19). Gastrointestinal involvement was defined as severe in cases of intussusception, gastrointestinal bleeding, or the need for enteral and/or parenteral nutrition support. The glomerular filtration rate (eGFR) was estimated using the bedside Schwartz formula (20). Decreased kidney function was defined as an estimated GFR below $90 \mathrm{~mL} / \mathrm{min}$ per $1.73 \mathrm{~m}^{2}(21)$. The highest proteinuria was measured in spot urine the day before kidney biopsy in $\mathrm{g} / \mathrm{L}$, and the protein-to-creatinine ratio was calculated in $\mathrm{mg} / \mathrm{mmol}$. NS was defined in accordance with France's national health agency (HAS) (22) as serum albumin $<30 \mathrm{~g} / \mathrm{L}$ and nephrotic range proteinuria (protein-to-creatinine ratio $>200$ $\mathrm{mg} / \mathrm{mmol}$ or $24-\mathrm{h}$ urinary protein $>50 \mathrm{mg} / \mathrm{kg}$ ).

All kidney biopsy reports were retrospectively reviewed by two experienced kidney pathologists and graded according to the ISKDC (Table 1) (15). Acute lesions (endocapillary proliferation and cellular crescents) were graded as $<50 \%$ or $>50 \%$ of the glomeruli. Endocapillary proliferation was defined by the presence of hypercellularity internal to the capillary wall with endothelial cell swelling, subendothelial expansion, and inflammatory cells, clearly leading to luminal narrowing. Interstitial fibrosis, glomerular sclerosis, and fibrous crescents were defined as chronic lesions. A second kidney biopsy was performed in cases of insufficient treatment efficacy at one month (less than a $50 \%$ reduction in the protein-to- 
creatinine ratio) or persistence of a protein-to-creatinine ratio $>100 \mathrm{mg} / \mathrm{mmol}$ at two months after the onset of treatment.

The treatments used were oral corticosteroids, methylprednisolone pulse therapy followed by oral corticosteroids, or other immunosuppressive therapy, and angiotensin-converting enzyme inhibitors (ACEis) or angiotensin receptor blockers (ARBs). Patients with ISKDC grade $\geq$ III were usually treated with methylprednisolone pulses followed by oral corticosteroid or other immunosuppressive therapy. Patients with ISKDC grade I were treated with only ACEis or ARBs, and ISKDC grade II was treated with oral corticosteroids most often (see Supplementary data S1).

Data were recorded during follow-up until the last documented outpatient visit. IgAV-N remission was defined as negative proteinuria (protein-to-creatinine ratio $<20 \mathrm{mg} / \mathrm{mmol}$ ) and normal kidney function (eGFR $\geq 90 \mathrm{ml} / \mathrm{min}$ per $1.73 \mathrm{~m}^{2}$ ). Kidney outcomes at the last follow-up were classified as follows: A. normal (no hypertension, normal proteinuria and kidney function); B. mild-to-moderate urinary abnormalities (protein-to-creatinine ratio between 20 and $200 \mathrm{mg} / \mathrm{mmol}$ ); C. more severe kidney impairment (protein-to-creatinine ratio $>200 \mathrm{mg} / \mathrm{mmol}$ and/or reduced eGFR $<90 \mathrm{ml} / \mathrm{min}$ per $1.73 \mathrm{~m}^{2}$ ).

\section{Statistical analyses}

Quantitative variables are expressed as medians and interquartile ranges (IQRs), and qualitative variables are expressed as counts and percentages. Cumulative incidence was calculated using the Kaplan-Meier method. Qualitative variables were compared using chi square or Fisher tests, and quantitative variables were compared using Student's or Mann-Whitney tests.

The relationship between the protein-to-creatinine ratio during follow-up and several baseline factors was evaluated by linear regression analysis. Based on prior knowledge and the literature, sex, age, gastrointestinal involvement, NS status, histological severity (ISKDC grade, endocapillary proliferation, cellular crescents, and interstitial fibrosis), time from IgAV-N diagnosis to corticosteroid therapy initiation, and treatments received were included in the model. Statistical significance was defined as $p<0.05$. The statistical analyses were performed using SPSS version 20.0 (SPSS Inc., Chicago, IL, USA).

\section{Results}

\section{Patient characteristics}

Patient characteristics at baseline are reported in Table 2. A total of 170 patients (101 males) with IgAV-N were included. The median age at diagnosis was 7.8 years (IQR 5.7-10.9). The median time from IgAV onset to IgAV-N diagnosis was 17 days (IQR 10-34).

The median highest protein-to-creatinine ratio was $369 \mathrm{mg} / \mathrm{mmol}$ (IQR 197-704). Forty-six patients (27.1\%) presented with NS. The median eGFR was $118 \mathrm{ml} / \mathrm{min}$ per $1.73 \mathrm{~m}^{2}$ (IQR 102-141). Only 14 
patients $(8.4 \%)$ had a decreased eGFR $<90 \mathrm{ml} / \mathrm{min}$ per $1.73 \mathrm{~m}^{2}$ at diagnosis.

The median time from IgAV-N diagnosis to kidney biopsy was 17 days (IQR 10-39). The kidney biopsy reports were reviewed by two pathologists (no full review of biopsies) and were classified as ISKDC grade I in 23 patients (13.5\%), grade II in 73 patients (42.9\%), grade III in 68 patients (40.0\%) including 44 patients with grade IIIA and 24 with grade IIIB, grade IV in two patients (1.2\%) and grade VI in four patients (2.4\%). Endocapillary proliferation was described in 125 patients, 87 patients with endocapillary proliferation observed in $<50 \%$ of the glomeruli and 38 patients with endocapillary proliferation in $>50 \%$ of the glomeruli. Chronic lesions were present in 42 patients (24.7\%). Specifically, interstitial fibrosis was present in 22 biopsies (12.9\%), glomerular sclerosis in 15 biopsies (8.8\%) with a median number of $5.5 \%$ (IQR 3.7-9.7) per biopsy, and fibrous crescents in 15 biopsies (8.8\%) with a median number of $6.3 \%$ (IQR 4.8-5.7) per biopsy. In patients with chronic lesions, the median time from IgAV-N diagnosis to kidney biopsy was 30 days (IQR 12-59) versus 17 days (IQR 9-32) in patients without chronic lesions $(p<0.01)$. The median follow-up duration was 21 months (IQR 12-39), which was similar for patients with and without chronic lesions.

\section{Treatment of IgAV-N}

Corticosteroids were administered orally in 153 patients (90.0\%) for a median of 4.6 months (IQR 3.9-6.4), with 103 patients $(60.6 \%)$ also receiving three methylprednisolone pulses. ACEis or ARBs were administered in 155 patients (91.2\%). Twenty-five patients (14.7\%) received other immunosuppressive treatments in addition to or following steroid therapy, as follows: cyclophosphamide (20 patients), mycophenolate mofetil (2 patients), intravenous immunoglobulin (2 patients), and azathioprine (1 patient). The median duration of any immunosuppressive drugs combined was 2.8 months (IQR 2.4-2.9). The median duration of cyclophosphamide treatment was 2.7 months (IQR 2.5-2.8). In 2 patients treated with mycophenolate mofetil, the duration of treatment was 19.4 months and 3.2 months, and in patients treated with azathioprine, the duration was 9.8 months.

One patient with a severe clinical and histological presentation was treated by plasma exchange (10 sessions). At 1 month from IgAV-N diagnosis, 5 patients received two methylprednisolone pulses. Three of them had already received methylprednisolone pulses at diagnosis of IgAV-N.

\section{Factors associated with proteinuria at diagnosis}

At diagnosis, children under 10 years $(p=0.029)$ and those with endocapillary proliferation in more than $50 \%$ of their glomeruli $(p=0.001)$ had a higher protein-to-creatinine ratio in the multivariate analysis (Table 3). In addition, patients with established NS at diagnosis had more severe histological lesions, with higher ISKDC grades as follows: 3.0 (IQR 2.0-4.0) vs. 2.0 (IQR 2.0-3.0) $(\mathrm{p}=0.004)$, a higher prevalence of extracapillary proliferation: $10.3 \%$ (IQR $0.0-20.6)$ vs. $5.3 \%$ (IQR 0.0-6.5) $(\mathrm{p}=0.03)$, and more extensive endocapillary proliferation: 39.3\% (IQR 20.7-55.0) vs. 23.3\% (IQR 0.0-33.3) ( $p=0.001)$ (Table 4).

\section{Follow-up results}


Overall, the cumulative prevalence of remission was $30 \%, 51 \%, 70 \%, 76 \%, 81 \%$ and $83 \%$ at $3,6,12,24,36$ and 48 months, respectively (Figure 1). Nineteen patients had at least one additional biopsy during follow-up. Among these patients with recurrent biopsies, three patients without chronic lesions but with endocapillary proliferation in the initial biopsy had interstitial fibrosis during follow-up biopsies.

In the multivariate analysis, interstitial fibrosis on initial kidney biopsy was associated with the protein-tocreatinine ratio at 3 months $(\beta=+178, p=0.008)$. In addition, the time between IgAV-N diagnosis and the introduction of corticosteroids was significantly associated with the protein-to-creatinine ratio at the 6month follow-up $(\beta=+0.1, p<0.0001)$; the shorter the time between IgAV-N diagnosis and the introduction of corticosteroids, the lower was the protein-to-creatinine ratio at 6 months.

(supplementary data S2).

\section{Outcome at last follow-up}

The median follow-up was 21 months, with $30 \%$ of patients being followed for more than 3 years. At the last follow-up, two-thirds of patients $(115 / 170,68 \%)$ had no kidney sequelae (no residual proteinuria or decreased kidney function, i.e., group A). Of these 115 patients, 105 were treated with oral corticosteroids, of whom $69(60 \%)$ also received methylprednisolone pulses, and $10(9 \%)$ received additional immunosuppressive therapy. Thirty percent of patients (51/170) had moderate urinary abnormalities (group B). Of these 51 patients, only five received ACEis, and 13 patients received several treatments (ACEis, corticosteroids, and immunosuppressants). Only 2 patients had more severe kidney impairment (group C). Both had severe IgAV-N with NS and an ISKDC grade IIIB kidney biopsy at IgAV-N onset. Two patients were lost to follow-up immediately after the diagnosis of IgAV-N.

At the last follow-up, the kidney outcome was significantly associated with confirmed NS at IgAV-N diagnosis $(p=0.045)$ and the presence of cellular crescents $(p=0.027)$ and chronic lesions such as glomerular sclerosis $(p=0.046)$ and fibrous crescents $(p=0.046)$ in the kidney biopsy (Table 5$)$.

\section{Discussion}

This study retrospectively examined a large paediatric cohort of patients with biopsy-proven IgAV-N and identified associations between clinical and histological presentations and kidney prognosis. The main findings are that endocapillary proliferation on initial kidney biopsy was associated with the severity of IgAV-N at diagnosis and that chronic glomerular changes and interstitial fibrosis on initial kidney biopsy were associated with a poorer medium-term kidney outcome. Approximately one-third of patients had persistent kidney disease (proteinuria in $30 \%$ of patients or decreased eGFR in $1 \%$ of patients) after a median follow-up of 21 months.

The demographic characteristics of our population are similar to those in other studies, with a predominance of male patients and a median onset age of 8 years $(11,13,23,24)$. In accordance with previous studies, kidney involvement occurred within 6 months following IgAV diagnosis in almost all our 
patients $(96 \%)(4,23,25)$. In our study, kidney biopsy was usually performed quickly after the diagnosis, with a median interval of 17 days. Acute histological lesions (mostly endocapillary proliferation and, less frequently, cellular crescents) were described in most of the biopsies. In contrast, chronic lesions (glomerular and tubular) were less common. In the literature, endocapillary lesions are rarely documented in IgAV-N and may be reversible by corticosteroids and immunosuppressive therapy in IgA vasculitis (26). In our study, endocapillary proliferation was the only acute lesion associated with the level of proteinuria at diagnosis in the multivariate analysis and therefore reflected the initial clinical severity. This association is not always mentioned in published studies. Recently, a French study by Delbet et al did not find any association between endocapillary proliferation and kidney prognosis (27). Conversely, cellular crescents have been identified as poor prognostic factors in some studies $(7,12,28-30)$, especially if crescents are present in more than $50 \%$ of glomeruli (31). In our study, crescents in the initial biopsy were more predictive of the longer-term kidney outcome than endocapillary proliferation was. In addition to acute lesions, some $25 \%$ of biopsies showed chronic histological lesions (glomerular changes and interstitial fibrosis). In patients with chronic lesions, the median time from IgAV-N diagnosis to kidney biopsy was twice as long as that in patients without chronic lesions (30 vs. 17 days). These results were similar to those in the studies by Hennies et al (23) and Delbet et al (27), which reported a longer delay between nephritis and kidney biopsy and a higher proportion of chronic lesions among children with worse outcomes. We also found that the presence of chronic lesions was significantly associated with a poorer kidney outcome, as other studies did (32). Therefore, the identification of chronic lesions on initial biopsies may reflect the duration of IgAV-N, regardless of clinical manifestations, suggesting a late diagnosis or indicating a silent period with kidney damage in IgAV-N before clinical symptoms. Additionally, some patients may develop chronic lesions more rapidly than others due to their genetic background favouring fibrotic healing from an inflammatory state.

According to these results, we suggest that endocapillary proliferation and chronic lesions be analysed in IgAV-N. In our cohort, $25 \%$ of patients with grade II ISKDC had persistent kidney disease at the last followup, despite receiving corticosteroid therapy. Coppo et al found CKD in 23\% of patients (adults and children) with grade II ISKDC after a follow-up of 4.8 years and stated that IgAV-N should not be considered a more benign condition in children than in adults (14). Additionally, Delbet et al found persistent proteinuria in $25 \%$ of these patients during the 1.5-year follow-up (25). The prognosis of patients with mild histological lesions (no crescents but mesangial and/or endocapillary proliferation) may often also be unfavourable in the long term and should not be underestimated. Therefore, these histological lesions should be taken into account in a new classification. The ISKDC classification, the reference currently for IgAV-N, is of limited prognostic value. Other histological classifications or biomarkers need further evaluations to better define the histological severity and improve the risk stratification in IgAV-N. In adult nephrology, the classification of Pillebout et al. is used to identify focal and diffuse endocapillary proliferation as the most frequent lesions in IgAV-N (33). Furthermore, given the pathophysiological and histological similarities between IgAV-N and IgA nephropathy and the limitations of the ISKDC classification, several authors have proposed using the Oxford classification in adults and children with IgAV-N (17,32,34). The Oxford classification assesses kidney pathology in terms of 
mesangial cellularity, endocapillary hypercellularity, glomerular sclerosis, and interstitial fibrosis (16). A significant association between the presence of endocapillary proliferation or interstitial fibrosis and longterm kidney prognosis has been reported using the Oxford classification (32). However, extracapillary proliferation, considered a marker of severity in IgAV-N, is not considered in this classification.

On the other hand, clinical features as risk factors for poor kidney outcome remain controversial. Several studies have reported that the clinical severity at diagnosis of IgAV-N is predictive of kidney outcome $(4,7,8,11,12,35,36)$. Narchi et al reported CKD in $19.5 \%$ of children with NS and only in $1.6 \%$ of children with isolated urinary abnormalities at diagnosis (4). In contrast, Tudorache et al found no association between initial clinical severity and long-term kidney prognosis (10). In our cohort, the presence of NS at diagnosis was significantly associated with persistent kidney disease after 21 months. Furthermore, the presence of NS was also significantly associated with initial histological severity, with increased endocapillary proliferation and cellular crescents, associated with a poorer kidney outcome, as described above $(7,12,28,29,31,37)$. These data suggest that corticosteroid treatment in IgAV-N patients with NS should not be delayed and that the decision for treatment should rely more on clinical presentation than on histological findings. Moreover, these findings question the usefulness of a kidney biopsy in cases of severe clinical features of IgAV-N. Kidney biopsy may be performed as a second step to identify lesions associated with poor prognosis and to adapt treatment. In accordance with the literature $(28,29,38,39)$ and because the 6-month protein-to-creatinine ratio was significantly associated with the delay of IgAV-N corticosteroid treatment, our analysis indirectly suggests that kidney outcomes may be improved by early treatment.

Our study has several limitations. These include the retrospective, multicentric and uncontrolled design of the study and the selection bias of only including patients with biopsy-proven IgAV-N. Patients with benign or moderate kidney impairment that improved spontaneously or with ACEi therapy were not included. There was likely an overrepresentation of severe cases of IgAV-N. All kidney biopsy reports were retrospectively reviewed by two experienced kidney pathologists, but there was no full review of slide biopsies. Moreover, the relatively short follow-up period of the study precludes an adequate assessment of long-term kidney outcomes.

In conclusion, in this retrospective multicentre cohort analysis, endocapillary proliferation on initial kidney biopsy was associated with the clinical severity of IgAV-N at diagnosis, and chronic lesions were associated with poorer short- and medium-term kidney outcomes. These lesions are not included in the ISKDC reference classification and should be considered to better delineate the disease severity in paediatric IgAV-N with a new histological classification. We suggest that corticosteroid treatment in IgAV$\mathrm{N}$ patients with NS should not be delayed by kidney biopsy.

\section{Abbreviations}

ACEi: angiotensin-converting enzyme inhibitor

ARB: angiotensin receptor blocker 
CKD: chronic kidney disease

EULAR: European League against Rheumatism

GFR: Glomerular filtration rate

IgAV: Immunoglobulin A vasculitis

IgAV-N: Immunoglobulin A vasculitis nephritis

IQR: interquartile range

ISKDC: International Study of Kidney Disease in Children

NS: nephrotic syndrome

\section{Declarations}

Acknowledgements: The authors thank the patients who participated in the study.

\section{Compliance with Ethical Standards}

Funding: None.

Conflict of interest: The authors declare that they have no conflicts of interest.

Ethical approval: The study was approved by the ethics committee of the French Society of Paediatrics (CER_SFP_2018_079-3).

Consent to participate: Informed consent was obtained from the parent(s)/legal representative(s) of all individual participants included in the study and, where appropriate, the patient provided written assent.

Availability of data and material: Statistical Package for Social Science software for Microsoft Windows (SPSS Inc., IBM, Chicago, IL)

Autor's contribution: S Clavé, M Sordet, M Tsimaratos, C Rousset-Rouvière and J Harambat contributed to the study conception and design. Material preparation and data collection were performed by $S$ Clavé and M Sordet. L Daniel and J Torrents were involved in the analysis of pathological data. M Boucekine conducted the data analysis. The first draft of the manuscript was written by S Clavé, M Tsimaratos, $C$ Rousset-Rouvière and $\mathrm{J}$ Harambat. All authors commented on previous versions of the manuscript. All authors have revised the manuscript critically for important intellectual content, have provided final approval of the manuscript version to be published, and agree to be accountable for all aspects of the manuscript.

\section{References}


1. Gardner-Medwin JMM, Dolezalova P, Cummins C, Southwood TR. Incidence of Henoch-Schönlein purpura, Kawasaki disease, and rare vasculitides in children of different ethnic origins. Lancet. 2002;360(9341):1197-202.

2. Saulsbury FT. Clinical update: Henoch-Schönlein purpura. Lancet. 2007;369(9566):976-8.

3. Jauhola O, Ronkainen J, Koskimies O, Ala-Houhala M, Arikoski P, Hölttä T, et al. Clinical course of extrarenal symptoms in Henoch-Schonlein purpura: a 6-month prospective study. Arch Dis Child. 2010;95(11):871-6.

4. Narchi H. Risk of long term renal impairment and duration of follow up recommended for HenochSchonlein purpura with normal or minimal urinary findings: a systematic review. Arch Dis Child. 2005;90(9):916-20.

5. Pohl M. Henoch-Schönlein purpura nephritis. Pediatr Nephrol. 2015 Feb;30(2):245-52.

6. Coppo R, Gianoglio B, Porcellini MG, Maringhini S. Frequency of renal diseases and clinical indications for renal biopsy in children (report of the Italian National Registry of Renal Biopsies in Children). Group of Renal Immunopathology of the Italian Society of Pediatric Nephrology and Group of Renal Immunopathology of the Italian Society of Nephrology. Nephrol Dial Transplant.1998;13(2):293-7.

7. Goldstein AR, White RH, Akuse R, Chantler C. Long-term follow-up of childhood Henoch-Schönlein nephritis. Lancet. 1992;339(8788):280-2.

8. Ronkainen J, Nuutinen M, Koskimies 0 . The adult kidney 24 years after childhood Henoch-Schönlein purpura: a retrospective cohort study. Lancet. 2002;360(9334):666-70.

9. Halling SFE, Söderberg MP, Berg UB. Henoch Schönlein nephritis: clinical findings related to renal function and morphology. Pediatr Nephrol. 2005;20(1):46-51.

10. Tudorache E, Azema C, Hogan J, Wannous H, Aoun B, Decramer S, et al. Even mild cases of paediatric Henoch-Schönlein purpura nephritis show significant long-term proteinuria. Acta Paediatr. 2015;104(8):843-8.

11. Mir S, Yavascan O, Mutlubas F, Yeniay B, Sonmez F. Clinical outcome in children with HenochSchönlein nephritis. Pediatr Nephrol. 2007;22(1):64-70.

12. Coppo R, Andrulli S, Amore A, Gianoglio B, Conti G, Peruzzi L, et al. Predictors of outcome in HenochSchönlein nephritis in children and adults. Am J Kidney. 2006;47(6):993-1003.

13. Butani L, Morgenstern BZ. Long-term outcome in children after Henoch-Schonlein purpura nephritis. Clin Pediatr. 2007;46(6):505-11.

14. Coppo R, Mazzucco G, Cagnoli L, Lupo A, Schena FP. Long-term prognosis of Henoch-Schönlein nephritis in adults and children. Italian Group of Renal Immunopathology Collaborative Study on Henoch-Schönlein purpura. Nephrol Dial Transplant. 1997;12(11):2277-83.

15. Counahan R, Winterborn MH, White RH, Heaton JM, Meadow SR, Bluett NH, et al. Prognosis of Henoch-Schönlein nephritis in children. Br Med J. 1977;2(6078):11-4. 
16. A Working Group of the International IgA Nephropathy Network and the Renal Pathology Society, Cattran DC, Coppo R, Cook HT, Feehally J, Roberts ISD, et al. The Oxford classification of IgA nephropathy: rationale, clinicopathological correlations, and classification. Kidney Int. 2009;76(5):534-45.

17. Xu K, Zhang L, Ding J, Wang S, Su B, Xiao H, et al. Value of the Oxford classification of IgA nephropathy in children with Henoch-Schönlein purpura nephritis. J Nephrol. 2018;31(2):279-86.

18. Ozen S, Pistorio A, lusan SM, Bakkaloglu A, Herlin T, Brik R, et al. EULAR/PRINTO/PRES criteria for Henoch-Schönlein purpura, childhood polyarteritis nodosa, childhood Wegener granulomatosis and childhood Takayasu arteritis: Ankara 2008. Part II: Final classification criteria. Ann Rheum Dis. 2010;69(5):798-806.

19. Flynn JT, Kaelber DC, Baker-Smith CM, Blowey D, Carroll AE, Daniels SR, et al. Clinical Practice Guideline for Screening and Management of High Blood Pressure in Children and Adolescents. Pediatrics. 2017;140(3):e20171904.

20. Schwartz GJ, Muñoz A, Schneider MF, Mak RH, Kaskel F, Warady BA, et al. New equations to estimate GFR in children with CKD. J Am Soc Nephrol. 2009;20(3):629-37.

21. Beck L, Bomback AS, Choi MJ, Holzman LB, Langford C, Mariani LH, et al. KDOQI US commentary on the 2012 KDIGO clinical practice guideline for glomerulonephritis. Am J Kidney Dis. 2013;62(3):40341.

22. Centre de Référence Syndrome Néphrotique Idiopathique. Protocole National de Diagnostic et de Soins (PNDS) Syndrome néphrotique idiopathique de l'enfant [Internet]. Available from: https://www.has-sante.fr/upload/docs/application/pdf/2016-04/pnds__syndrome_nephrotique_idiopatique_de_lenfant_2016-04-29_15-02-42_382.pdf

23. Hennies I, Gimpel C, Gellermann J, Möller K, Mayer B, Dittrich K, et al. Presentation of pediatric Henoch-Schönlein purpura nephritis changes with age and renal histology depends on biopsy timing. Pediatr Nephrol. 2018;33(2):277-86.

24. Wakaki H, Ishikura K, Hataya H, Hamasaki Y, Sakai T, Yata N, et al. Henoch-Schönlein purpura nephritis with nephrotic state in children: predictors of poor outcomes. Pediatr Nephrol. 2011;26(6):921-5.

25. Delbet JD, Hogan J, Aoun B, Stoica I, Salomon R, Decramer S, et al. Clinical outcomes in children with Henoch-Schönlein purpura nephritis without crescents. Pediatr Nephrol. 2017;32(7):1193-9.

26. Shen X-H, Liang S-S, Chen H-M, Le W-B, Jiang S, Zeng C-H, et al. Reversal of active glomerular lesions after immunosuppressive therapy in patients with IgA nephropathy: a repeat-biopsy based observation. J Nephrol. 2015;28(4):441-9.

27. Delbet J-D, Geslain G, Auger M, Hogan J, Salomon R, Peuchmaur M, et al. Histological prognostic factors in children with Henoch-Schönlein purpura nephritis. Pediatr Nephrol. 2020;35(2):313-20.

28. Niaudet P, Habib R. Methylprednisolone pulse therapy in the treatment of severe forms of SchönleinHenoch purpura nephritis. Pediatr Nephrol. 1998;12(3):238-43. 
29. Kawasaki Y, Suzuki J, Sakai N, Nemoto K, Nozawa R, Suzuki S, et al. Clinical and pathological features of children with Henoch-Schoenlein purpura nephritis: risk factors associated with poor prognosis. Clin Nephrol. 2003;60(3):153-60.

30. Edström Halling S, Söderberg MP, Berg UB. Predictors of outcome in Henoch-Schönlein nephritis. Pediatr Nephrol. 201025(6):1101-8.

31. Rieu P, Noël LH. Henoch-Schönlein nephritis in children and adults. Morphological features and clinicopathological correlations. Ann Med Interne. 1999;150(2):151-9.

32. Kim CH, Lim BJ, Bae YS, Kwon YE, Kim YL, Nam KH, et al. Using the Oxford classification of IgA nephropathy to predict long-term outcomes of Henoch-Schönlein purpura nephritis in adults. Mod Pathol. 2014;27(7):972-82.

33. Pillebout E, Thervet E, Hill G, Alberti C, Vanhille P, Nochy D. Henoch-Schönlein Purpura in adults: outcome and prognostic factors. J Am Soc Nephrol. 2002;13(5):1271-8.

34. Inagaki K, Kaihan AB, Hachiya A, Ozeki T, Ando M, Kato S, et al. Clinical impact of endocapillary proliferation according to the Oxford classification among adults with Henoch-Schönlein purpura nephritis: a multicenter retrospective cohort study. BMC Nephrol. 2018;19(1).

35. Ronkainen J, Ala-Houhala M, Huttunen NP, Jahnukainen T, Koskimies O, Ormälä T, et al. Outcome of Henoch-Schoenlein nephritis with nephrotic-range proteinuria. Clin Nephrol. 2003;60(2):80-4.

36. Koskela M, Ylinen E, Ukonmaanaho E-M, Autio-Harmainen H, Heikkilä P, Lohi J, et al. The ISKDC classification and a new semiquantitative classification for predicting outcomes of HenochSchönlein purpura nephritis. Pediatr Nephrol. 2017;32(7):1201-9.

37. Huang $X, M a L$, Ren P, Wang $H$, Chen L, Han H, et al. Updated Oxford classification and the international study of kidney disease in children classification: application in predicting outcome of Henoch-Schönlein purpura nephritis. Diagn Pathol. 2019;14(1).

38. Shin JI, Park JM, Kim JH, Lee JS, Jeong HJ. Factors affecting histological regression of crescentic Henoch-Schönlein nephritis in children. Pediatr Nephrol. 2006;21(1):54-9.

39. Davin J-C, Coppo R. Henoch-Schönlein purpura nephritis in children. Nat Rev Nephrol. 2014;10(10):563-73.

\section{Tables}

\section{Table 1. ISKDC classification (15)}




\begin{tabular}{|ll|}
\hline Grade & \\
\hline I & Minimal glomerular abnormalities \\
\hline II & Mesangial proliferation \\
\hline III & Mesangial proliferation with $<50 \%$ crescentic glomeruli \\
\hline IIIA & Focal segmental mesangial proliferation \\
\hline IIIB & Diffuse mesangial proliferation \\
\hline IV & Mesangial proliferation with $50 \%-75 \%$ crescentic glomeruli \\
\hline V & Mesangial proliferation with $>75 \%$ crescentic glomeruli \\
\hline VI & Membranoproliferative-like lesions \\
\hline
\end{tabular}

Table 2. Baseline characteristics of the study population 


\begin{tabular}{|c|c|}
\hline & $\mathrm{n}(\%)$ \\
\hline$N=170$ & Median [Q1; Q3] \\
\hline Age (years) & $7.8[5.7 ; 10.9]$ \\
\hline Boys & $101(59.4 \%)$ \\
\hline Joint involvement & $131 / 164(79.9 \%)$ \\
\hline \multicolumn{2}{|l|}{ Gastro-intestinal involvement } \\
\hline No severe & $92 / 164(56.1 \%)$ \\
\hline Severe & $42 / 164(25.5 \%)$ \\
\hline Orchitis & $24(23.8 \%)$ \\
\hline Time from IgAV to IgAV-N (days) & $17[10.0 ; 34.0]$ \\
\hline Time from IgAV-N to kidney biopsy & $17[10.0 ; 39.0]$ \\
\hline Hypertension & $11 / 168(6.5 \%)$ \\
\hline Acute kidney injury & $14 / 167(8.4 \%)$ \\
\hline GFR $\left(\mathrm{ml} / \mathrm{min}\right.$ per $\left.1.73 \mathrm{~m}^{2}\right)$ & $117.8[101.6 ; 140.9]$ \\
\hline Protein-to-creatinine ratio $(\mathrm{mg} / \mathrm{mmol})$ & $369.3[197.5 ; 704.1]$ \\
\hline Nephrotic syndrome & $46(27.1 \%)$ \\
\hline Macroscopic haematuria & $25(14.8 \%)$ \\
\hline \multicolumn{2}{|l|}{ ISKDC grade } \\
\hline I & $23(13.5 \%)$ \\
\hline II & $73(42.9 \%)$ \\
\hline$I I I A-I I I B$ & $44(25.9 \%)-24(14.1 \%)$ \\
\hline IV & $2(1.2 \%)$ \\
\hline VI & $4(2.4 \%)$ \\
\hline \multicolumn{2}{|l|}{ Endocapillary proliferation } \\
\hline$<50 \%$ of the glomeruli & $87(51.2 \%)$ \\
\hline$>50 \%$ of the glomeruli & $38(22.4 \%)$ \\
\hline Interstitial fibrosis & $22(12.9 \%)$ \\
\hline Glomerular sclerosis & 15 (8.8\%) \\
\hline
\end{tabular}

Page 16/21 
Table 3. Factors associated with proteinuria at diagnosis 


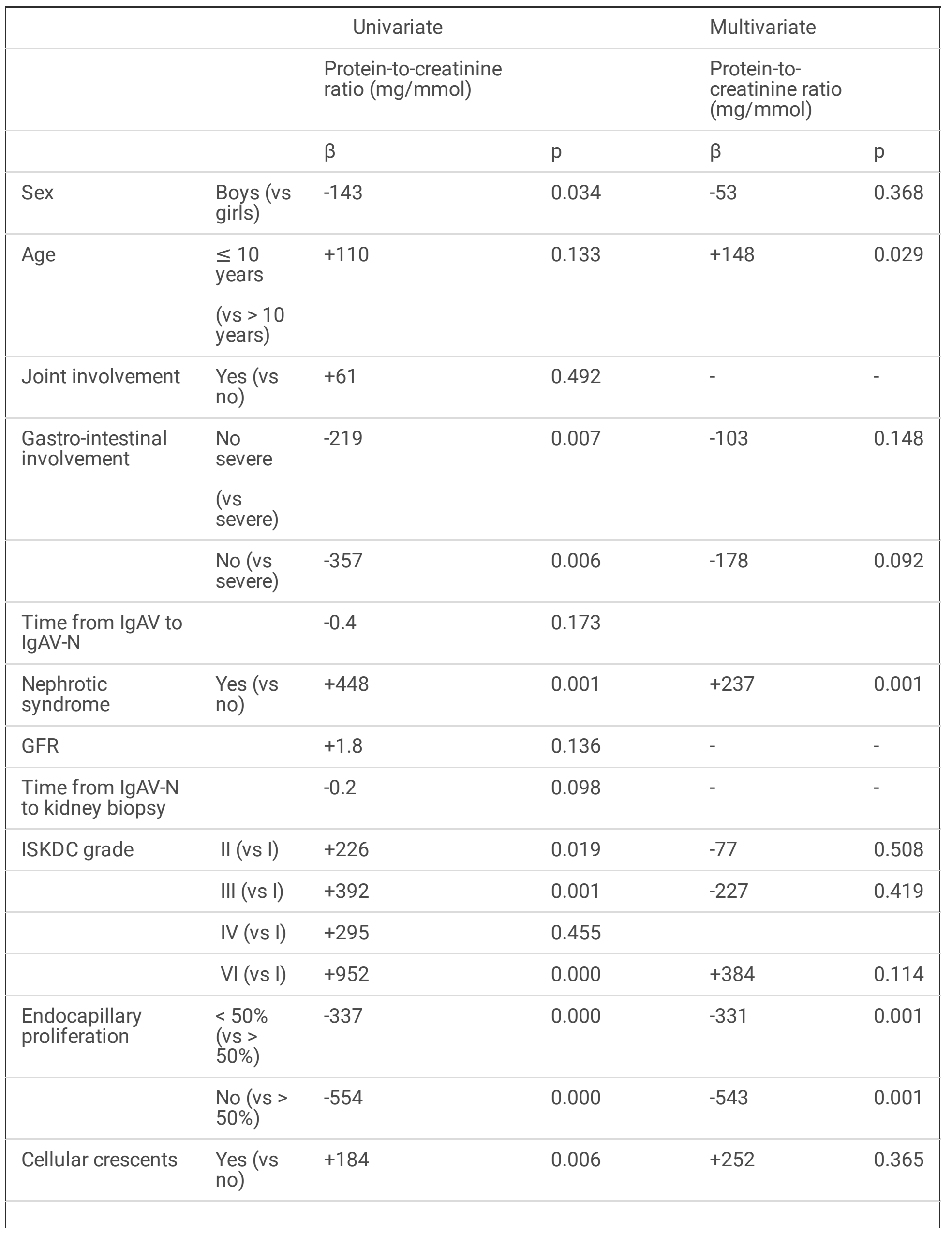




\begin{tabular}{|lccccc|} 
Interstitial fibrosis & $\begin{array}{l}\text { Yes (vs } \\
\text { no) }\end{array}$ & +97 & 0.352 & -52 & 0.565 \\
\hline $\begin{array}{l}\text { Glomerular } \\
\text { sclerosis }\end{array}$ & +5 & 0.600 & - & - \\
\hline Fibrous crescents & +18 & 0.080 & - & - \\
\hline
\end{tabular}

Table 4. Associations between initial clinical and histological data

\begin{tabular}{|c|c|c|c|c|}
\hline & & \multicolumn{3}{|c|}{ Nephrotic syndrome } \\
\hline & & Yes & \multicolumn{2}{|l|}{ No } \\
\hline & & Median (Q1; Q3) & Median (Q1; Q3) & $\mathrm{p}$ \\
\hline ISKDC grade & & $3.0[2.0 ; 4.0]$ & $2.0[2.0 ; 3.0]$ & 0.004 \\
\hline Endocapillary proliferation & & $39.3[20.7 ; 55.0]$ & $23.3[0.0 ; 33.3]$ & 0.001 \\
\hline Cellular crescents & & $10.3[0.0 ; 20.6]$ & $5.3[0.0 ; 6.5]$ & 0.030 \\
\hline \multirow[t]{2}{*}{ Interstitial fibrosis } & Yes & $6(13 \%)$ & $13(11.5 \%)$ & 0.786 \\
\hline & No & $40(87 \%)$ & $100(88.5 \%)$ & \\
\hline
\end{tabular}

Table 5. Associations between initial clinical and histological data and renal outcome at last follow-up 


\begin{tabular}{|c|c|c|c|c|}
\hline & & $A^{a}$ & $\mathrm{~B}^{\mathrm{b}}+\mathrm{C}^{\mathrm{c}}$ & $\mathrm{p}$ \\
\hline & & $n=115$ & $n=51+2$ & \\
\hline \multirow[t]{2}{*}{ Protein-to-creatinine ratio $(\mathrm{mg} / \mathrm{mmol})$} & $20-200$ & $25(64.1 \%)$ & $14(35.9 \%)$ & 0.429 \\
\hline & $>200$ & $85(69.7 \%)$ & $35+2(30.3 \%)$ & \\
\hline \multirow[t]{2}{*}{ Nephrotic syndrome } & Yes & $27(58.7 \%)$ & $17+2(41.3 \%)$ & 0.045 \\
\hline & No & $88(72.1 \%)$ & $34(27.9 \%)$ & \\
\hline \multirow[t]{6}{*}{ ISKDC grade } & 1 & $15(68.2 \%)$ & $7(31.8 \%)$ & 0.177 \\
\hline & II & $54(76.1 \%)$ & $17(23.9 \%)$ & \\
\hline & IIIA & $26(59.1 \%)$ & $18(40.9 \%)$ & \\
\hline & IIIB & $15(62.5 \%)$ & $7+2(37.5 \%)$ & \\
\hline & IV & $1(33.3 \%)$ & $2(66.6 \%)$ & \\
\hline & $\mathrm{VI}$ & $4(100 \%)$ & - & \\
\hline \multirow[t]{3}{*}{ Endocapillary proliferation } & No & $27(62.8 \%)$ & $16(37.2 \%)$ & 0.497 \\
\hline & $<50 \%$ & $63(72.4 \%)$ & $24(27.6 \%)$ & \\
\hline & $>50 \%$ & $25(65.8 \%)$ & $11+2(34.2 \%)$ & \\
\hline \multirow[t]{2}{*}{ Cellular crescents } & Yes & $40(58.8 \%)$ & $26+2(41.2 \%)$ & 0.027 \\
\hline & No & $75(75.0 \%)$ & $25(25.0 \%)$ & \\
\hline \multirow[t]{2}{*}{ Interstitial fibrosis } & Yes & $12(54.5 \%)$ & $9+1(45.5 \%)$ & 0.132 \\
\hline & No & 103 (70.5\%) & $43(29.5 \%)$ & \\
\hline \multirow[t]{2}{*}{ Glomerular sclerosis } & Yes & $7(46.7 \%)$ & $8(53.3 \%)$ & 0.046 \\
\hline & No & $108(93.9 \%)$ & $45(6.1 \%)$ & \\
\hline \multirow[t]{2}{*}{ Fibrous crescents } & Yes & $7(46.7 \%)$ & $7+1(53.3 \%)$ & 0.046 \\
\hline & No & $108(93.9 \%)$ & $45(6.1 \%)$ & \\
\hline \multirow[t]{2}{*}{ Methylprednisolone pulses } & Yes & $69(67.0 \%)$ & $32+2(33.0 \%)$ & 0.608 \\
\hline & No & $46(70.8 \%)$ & $19(29.2 \%)$ & \\
\hline \multirow[t]{2}{*}{ Immunosuppressives treatment } & Yes & $10(40.0 \%)$ & $13+2(60.0 \%)$ & 0.001 \\
\hline & No & 105 (73.4) & 38 (26.6\%) & \\
\hline
\end{tabular}

$\mathrm{a}=$ normal (no hypertension, normal urine and renal function); $\mathrm{b}=$ mild-to-moderate urinary abnormalities (protein-to-creatinine ratio between $20-200 \mathrm{mg} / \mathrm{mmol}$ ); c = more severe kidney impairment (protein-to- 
creatinine ratio $>200 \mathrm{mg} / \mathrm{mmol}$ and/or reduced eGFR $<90 \mathrm{ml} / \mathrm{min}$ per $1.73 \mathrm{~m}^{2}$ )

\section{Figures}

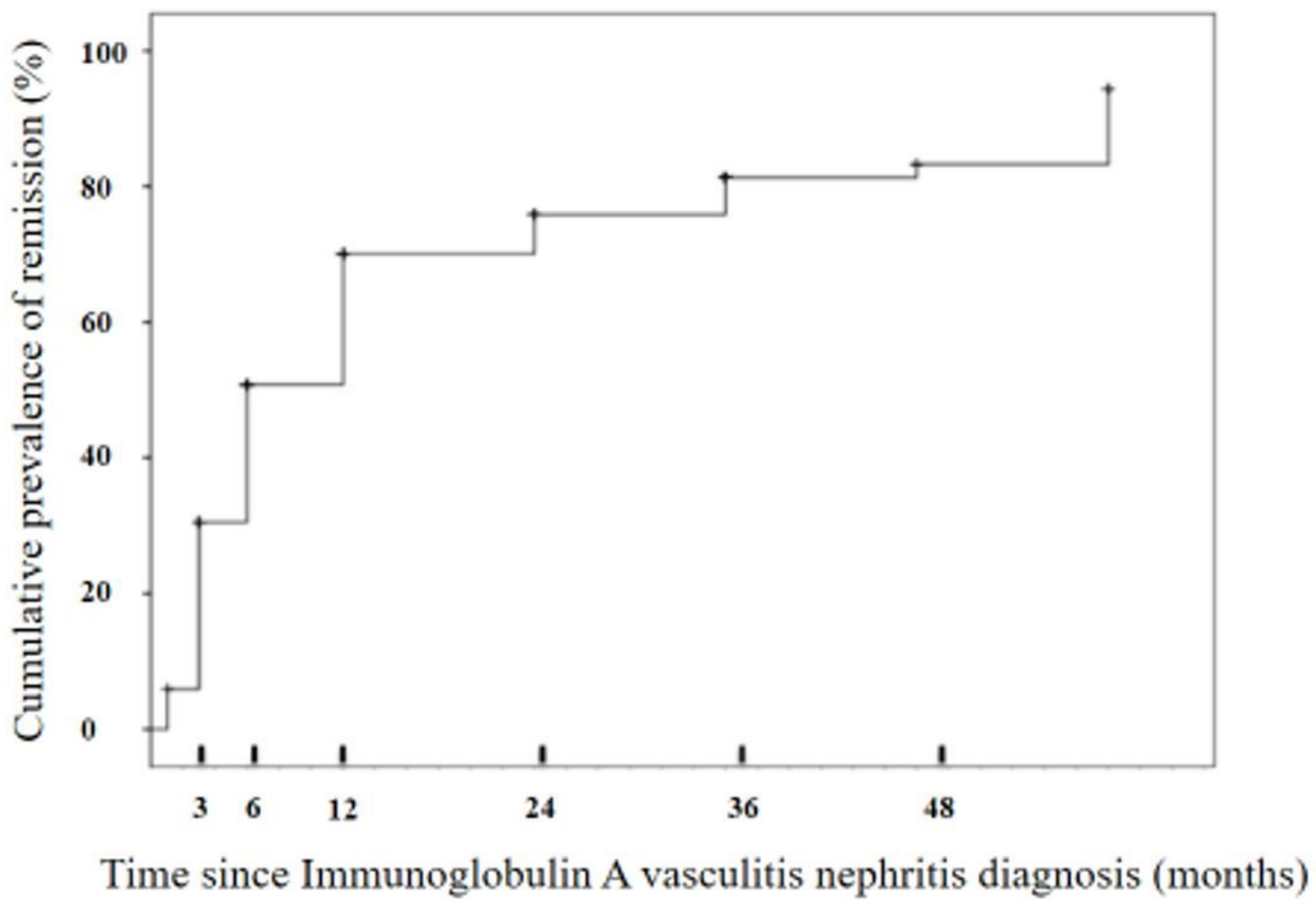

Figure 1

Cumulative prevalence of remission

\section{Supplementary Files}

This is a list of supplementary files associated with this preprint. Click to download.

- SupplementarydataS1.doc

- SupplementarydataS2.docx 